\title{
НЕФРОГЕННЫЙ СИНДРОМ НЕАДЕКВАТНОГО АНТИДИУРЕЗА КАК ПРИЧИНА ЖИЗНЕУГРОЖАЮЩЕЙ ГИПОНАТРИЕМИИ В ДЕТСКОМ ВОЗРАСТЕ
}

${ }^{1,3}$ Тихонович Ю.В., ${ }^{1}$ Петряйкина Е.Е., ${ }^{1}$ Рыбкина И.Г., ${ }^{1}$ Князева Т.Т.,

${ }^{2}$ Тюльпаков А.Н.

${ }^{1}$ Морозовская детская городская клиническая больница Департамента Здравоохранения Москвы, г. Москва

${ }^{2}$ ФБГУ НМИЦ Эндокринологии Минздрава России, г. Москва

${ }^{3}$ Университетская детская клиническая больница Первого МГМУ

им. И.М. Сеченова, г. Москва

Нефрогенный синдром неадекватного антидиуреза (НСНАД) - редкая Х-сцепленная форма нарушения водного баланса, обусловленная активирующими мутациями гена рецептора вазопрессина 2-го типа (AVPR2). Постоянная активация AVPR2 приводит к неадекватной реабсорбции свободной жидкости, повышению удельного веса мочи и персистирующей эуволемической гипоосмолярной гипонатриемии.

Клинические проявления НСНАД варьируют от бессимптомной гипонатриемии с олигодипсией до жизнеугрожающей гипонатриемической энцефалопатии у новорожденных и детей первых лет жизни.

Мы приводим описание тяжелой гипонатриемии у пациента 2 лет как проявления НСНАД в результате гемизиготной мутации с.409C $>\mathrm{T}$ p.R137C в гене $A V P R 2$.

Ключевые слова: гипонатриемия, нефрогенный синдром неадекватного антидиуреза, рецептор вазопрессина 2-го типа

Meтоды $и$ материальл. С помощью полимеразной цепной реакции (ПЦР) амплифицировали фрагменты геномной ДНК, охватывающие экзоны 1-3 гена AVPR2 с примыкающими участками интронов.

Продукты ПЦР очищали с использованием набора Cleanup Standard («Евроген», Россия) с последующим секвенированием на автоматическом секвенаторе ABI Genetic Analyzer 3130 («Applied Biosystems», США).

Результаты: ребенок поступил в отделение реанимации впервые в связи с впервые возникшим афебрильным судорожным синдромом. Учитывая наличие стойкой гипонатриемии до 111-120 ммоль/л на фоне нормокалиемии, снижения осмоляльности плазмы, повышения удельного веса мочи до 1010-1025 и отсутствия изменений в гормональном профиле, клинически заподозрен НСНАД. Диагноз подтвержден результатом молекулярно-генетического исследования.

Bblвoдbl: НСНАД должен быть включен в круг дифференцируемых заболеваний у пациентов с синдромом гипонатриемии. Использование генетического исследования необходимо для точной верификации диагноза, определения оптимальной тактики ведения пациентов и проведения пренатальной диагностики при дальнейшем планировании семьи. 